\title{
A new approach for dam safety assessment using the extended cloud model
}

\author{
Liansheng Sang \\ Hefei University of Technology \\ Jun Wang \\ Hefei University of Technology \\ Jueyi Sui ( $\sim$ jueyi.sui@unbc.ca ) \\ University of Northern British Columbia \\ Mauricio Dziedzic \\ University of Northern British Columbia
}

\section{Research Article}

Keywords: Extended cloud model (ECM), Extended Analytic Hierarchy Process (EAHP), Concrete faced rockfill dam, Safety trend assessment

Posted Date: January 17th, 2022

DOI: https://doi.org/10.21203/rs.3.rs-1065081/v1

License: (c) (1) This work is licensed under a Creative Commons Attribution 4.0 International License. Read Full License

Version of Record: A version of this preprint was published at Water Resources Management on March 31st, 2022. See the published version at https://doi.org/10.1007/s11269-022-03124-1. 


\section{Abstract}

To address the uncertainty problem in the assessment of the overall safety trend of dams and in the selection of safety trend warning indicators, an Extended Cloud Model (ECM) combined with the Extended Analytic Hierarchy Process (EAHP) method is proposed in this study. In this new approach, different factors reflecting dam safety monitoring have been considered as a fuzzy system. Considering the characteristics of the forward cloud model and the backward cloud model, the original data have been extended to classify the division interval and determine the respective indicators. The weight distribution for each indicator level has been determined using the EAHP method. The model developed was applied to evaluate the safety trend of the Jilintai concrete faced rockfill dam. Simulation results showed that the proposed model can generate reliable results, in addition to being used to assess the uncertainty problem and the safety warning indicator. The proposed model is also more flexible and easier to use than other methods.

\section{Introduction}

Large dams are important hydraulic structures for flood control, power generation, water supply and irrigation. Due to varying design criteria, changing natural conditions, and natural aging, dams may incur growing safety hazards as they age. Thus, it is very important to continuously assess dam conditions to ensure its safety (Gu et al., 2018, 2020)

There are many factors that influence dam safety. To comprehensively conduct dam safety assessment, a group of indicators for dam safety monitoring and risk warning are required, such as seepage through the dam and its foundation, dam deformation, stress-strain behaviors of the dam, among others. The main methods for determining these indicators are the confidence interval method, the typical small probability method, the limit state method (Wu et al., 1989), and the finite element method (Chen et al., 2021). Gu \& Wang (2017) established a risk management based method for determining the indicator for the deformation of concrete dams based on the risk of concrete dams theory. Each of these methods has limitations. For instance, the confidence interval method and the typical small probability method are only feasible if the series of observations is long enough and unfavorable loading combinations are actually encountered. Under such conditions, the predicted indicators will be close to the extreme values. However, there are no rules to follow for determining the failure probability. When the limit state method is used to estimate the indicators, large amounts of data and factors are required regarding the physical and mechanical characteristics of the dam and its foundation (Yang et al., 2002). The indicators based on risk management theory also take into account the situation of the region downstream of the dam, and when changes occur, such as social and economic development in the region, the indicators need to be updated. Thus, indicators based on risk management theory may be seen as lacking flexibility to adjust to changing conditions.

The Analytic Hierarchy Process (AHP) was proposed by Saaty in the 1970s and is commonly used to determine indicator weights (Araujo et al., 2021; Yee et al., 2021; Radhika and Sudha, 2021; Neji Nouha et 
al., 2021). When an assessment matrix for comparing indicators is developed based on pairwise comparisons conducted by experts in the field, the resulting weighting factors may have a strong subjective uncertainty due to different experiences and perceptions of different experts. Topology is a discipline that can be used to solve paradoxical problems by creating matter elements and relation elements. The subject, its features and data are considered as three important elements to describe the objective matter. By using intervals instead of discrete values, researchers have combined the traditional AHP with topology to construct an assessment matrix to obtain the weight values of indicators of each level. This method is called the Extended Analytic Hierarchy Process (EAHP), and the indicator weights thus obtained are considered more objective (Dong et al., 2021).

Evaluating dam safety trend is a complex process with multiple factors in multiple levels, filled with stochasticity and fuzziness. To solve the fuzzy and stochastic aspect of the uncertainty, a cloud model theory has been proposed based on probability theory and fuzzy mathematics to achieve a reciprocal transformation of mapping relationships between qualitative concepts and quantitative assessment ( $\mathrm{Li}$ et al., 1995). Cloud models have been applied in the assessment of dam foundation (Li et al., 2017), comprehensive multi-level fuzzy assessment of reservoir-induced earthquakes (Zhang et al., 2014), mapping for landslide susceptibility (Yan et al., 2019), assessment of rocky slope stability (Liu et al., 2014), among other applications (Yan et al., 2019; Wu et al., 2021; Peng et al., 2020). Cloud models have also been applied to the comprehensive assessment of dam safety (Li et al., 2014; He et al., 2016, He et al., 2018), with good results being reported. Although the models developed for dam safety assessment can be applied for assessing the safety of some dams, these models can only give one single factor describing the overall assessment result, and are unable to provide a comprehensive assessment regarding the safe operation of dams, since this is a multifactor issue. Indicators reflecting different aspects of the operation of dams should be considered.

Single-indicator warning methods are unable to reflect all information regarding dam safety. An overall assessment of the operational level of a dam cannot be used to determine whether or not the dam will deteriorate in the future. In order to conduct a precise dam safety assessment, it is important to track multiple factors. Therefore, in order to permit updating, in real-time or periodically, the assessment of the trend of dam safety, an Extended Cloud Model (ECM) has been developed employing the EAHP method. The established ECM has the advantage of being flexible and adaptable.

\section{Assessment System For Safety Trend Of Dams}

Developing the assessment system for dam safety trend is a complex task. The accuracy of the assessment system depends mainly on the selection of indicators. These indicators should be representative and concise. In engineering practice, the indicators for dam safety assessment should cover the following five parts: environmental variables, dam seepage, dam deformation, face deformation, and stress-strain (Yang et al., 2010). Considering these criteria, 35 indicators were selected. For instance, among these 35 indicators, the seepage indicators included seepage both in the left and 
right bank, as well as through the dam body. The selected indicators are presented in Figure 1 and Table 1.

Table 1

Indicators and corresponding factors

\begin{tabular}{|c|c|c|c|}
\hline $\begin{array}{l}\text { Reservoir water level } \\
c_{11}\end{array}$ & DC-1-01 & $\begin{array}{l}\text { Seepage } \\
c_{21}\end{array}$ & WE-1 \\
\hline \multirow{4}{*}{$\begin{array}{l}\text { Dam foundation seepage } \\
C_{22}\end{array}$} & P-1-06 & \multirow{5}{*}{$\begin{array}{l}\text { Seepage around the dam } \\
C_{23}\end{array}$} & UP-1-13 \\
\hline & P-1-26 & & UP-1-24 \\
\hline & P-1-30 & & SY-1 \\
\hline & $P-1-31$ & & UP-1-08 \\
\hline \multirow[t]{3}{*}{ Horizontal displacement $C_{31}$} & ID-1-02 & & UP-1-29 \\
\hline & ID-1-11 & \multirow{3}{*}{$\begin{array}{l}\text { Sedimentation } \\
C_{32}\end{array}$} & TC-1-11 \\
\hline & ID-1-13 & & TC-1-14 \\
\hline \multirow{6}{*}{$\begin{array}{l}\text { Perimeter joint } \\
C_{41}\end{array}$} & JR-1-02-1 & & TC-1-18 \\
\hline & JR-1-07-1 & \multirow{3}{*}{$\begin{array}{l}\text { Vertical joint } \\
C_{42}\end{array}$} & $\mathrm{~J}-1-12$ \\
\hline & JR-1-09-2 & & $\mathrm{J}-1-22$ \\
\hline & JR-1-10-2 & & $\mathrm{J}-1-27$ \\
\hline & $J R-1-02-3$ & \multirow{3}{*}{$\begin{array}{l}\text { Reinforcement stress } \\
C_{51}\end{array}$} & $R-1-06$ \\
\hline & JR-1-11-3 & & $\mathrm{R}-1-10$ \\
\hline \multirow{3}{*}{$\begin{array}{l}\text { Face deformation } \\
C_{43}\end{array}$} & TM-1-04 & & $\mathrm{R}-1-13$ \\
\hline & TM-1-11 & \multirow{3}{*}{$\begin{array}{l}\text { Concrete strain } \\
C_{52}\end{array}$} & S3-1-02-3 \\
\hline & TM-1-20 & & S3-1-05-1 \\
\hline - & - & & S3-1-09-2 \\
\hline
\end{tabular}

\section{Ecm-eahp Assessment Method}

\subsection{Concepts and numerical characteristics of the cloud model}

Setting up a quantitative universe $U$ which is represented by an exact value $C$ is a qualitative concept on $U$. If $\forall x \in U$ and $x$ is a one-time random event on the qualitative concept $C$, the certainty degree of $x$ on $C$ is a random number with a stable propensity, and $x$ is called a cloud drop (Li et al., 1995). Eq. 1 defines $\mu$, 
$\mu=\exp \left[-\frac{\left(x-E_{x}\right)^{2}}{2\left(E_{n}\right)^{2}}\right]$

The cloud model has three important characteristics: expectation $\left(E_{x}\right)$, entropy $\left(E_{n}\right)$, and hyper entropy $\left(H_{e}\right)$. Expectation $\left(E_{X}\right)$ is the symmetrical axis of the cloud model and represents the most likely events, which are the most typical sample events. Entropy $\left(E_{n}\right)$ is a representation of the uncertainty of the events, which is the range of cloud drop values that the qualitative concept can assume. The hyper entropy $\left(H_{e}\right)$ represents the uncertainty of the cloud droplets. It is the thickness of the cloud level. The relationship between expectation $\left(E_{x}\right)$, entropy $\left(E_{n}\right)$ and hyper entropy $\left(H_{e}\right)$ in the cloud model are shown in Figure 2.

\subsection{Introduction to the Extended Cloud Model (ECM)}

The ECM is based on the reciprocal transformation of qualitative concepts and quantitative relationships using both forward and inverse cloud models. In the process of transforming the forward cloud model from the qualitative concept to quantitative relationship, the cloud drops of unfavorable events in the cloud map are divided into affiliation scope according to the principle of $3 \sigma$, and the inverse cloud model is reapplied to transform them into qualitative concepts (levels 1 to 4 ). From the new qualitative concept (levels 1 to 4), the forward cloud model is again used to complete two transformations from the qualitative concept to the quantitative relationship. The index values of each level are obtained from the perspective probability of occurrence, and the index Extended Cloud Diagram is shown in Figures 3a and $3 b$.

Indicator values can be obtained by extracting the cloud drops of neighboring classes with a distance between two cloud drops less than 0.5 and 0.05 in horizontal and vertical coordinates, respectively. The expected value of their horizontal coordinates is taken as the indicator value, as illustrated in Fig. 3 for $\mathrm{G}_{1}$, $\mathrm{G}_{2}$, and $\mathrm{G}_{3}$.

\subsection{EAHP}

\subsubsection{Extended Analytic Hierarchy Process steps}

The matrix for pair-wise comparisons was constructed according to the scale $\left(b_{i j}\right)$ proposed by Saaty et al. (2016) and the judgment principle. By using the 1 9 scale to define intervals instead of discrete values in Table 2, the judgment matrix $B=\left[b_{i j}\right]_{\text {max }}(i, j=1,2, \ldots m)$ has been constructed, where $b_{i j}=\left[b_{i j}{ }^{-}, b_{i j}{ }^{+}\right]$is an interval. Values 2, 4, 6 and 8 represent the medians of the judgment results of two adjacent intervals. For indicators describing the same attribute, to assess the importance of each indicator by using pair-wise comparison, such as the assessment of $m$ indicators inside of the subset $C=\left\{C_{1}, C_{2}, C_{3}, \ldots, C_{m}\right\}$ by using a range of importance scales to represent judgment results based on experts' experience, and the values are taken at the symmetrical positions of the judgment matrix (Eq. 2). 


$$
b_{j i}=1 / b_{i j}=\left[1 / b_{i j}^{+}, 1 / b_{i j}^{-}\right]
$$

Table 2

Judgement scale (Saaty et al., 2016)

\begin{tabular}{|ll|}
\hline Value & Criteria \\
\hline 1 & Elements are equally important \\
\hline 3 & The former element is slightly more important than the latter element \\
\hline 5 & The former element is more important than the latter element \\
\hline 7 & The former element is significantly more important than the latter element \\
\hline 9 & The former element is extremely more important than the latter \\
\hline
\end{tabular}

Eq. 3 shows the pair-wise comparison matrix.

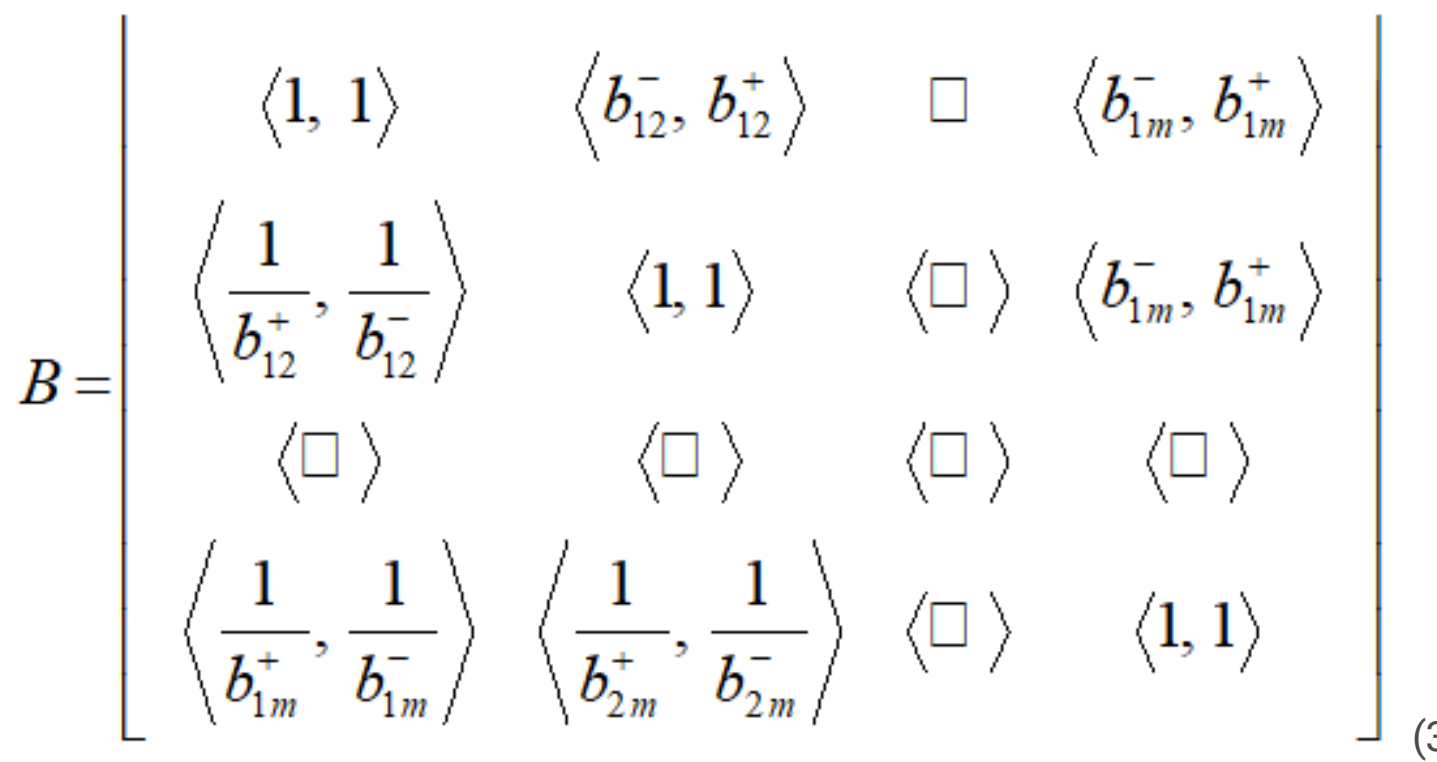

\subsubsection{Determination of indicator weights}

If $\lambda^{-}, \lambda^{+}$are the maximum eigenvalues of matrix $B$, then $\lambda=\left[\lambda^{-}, \lambda^{+}\right]$is the interval eigenvalue of the matrix $B$. By setting $x=\left[x^{-}, x^{+}\right]$to be the maximum eigenvector corresponding to the maximum eigenvalue of $B$, Eq. 4 and Eq. 5 are defined.

$\tilde{x}^{-}=\left(\sum_{j=1}^{m} \frac{b_{1 j}^{-}}{\sum_{j=1}^{m} b_{i j}^{-}}, \sum_{j=1}^{m} \frac{b_{2 j}^{-}}{\sum_{j=1}^{m} b_{i j}^{-}}, \Lambda, \sum_{j=1}^{m} \frac{b_{m j}^{-}}{\sum_{j=1}^{m} b_{i j}^{-}}\right)^{T}$ 


$$
\tilde{x}^{+}=\left(\sum_{j=1}^{m} \frac{b_{1 j}^{+}}{\sum_{j=1}^{m} b_{i j}^{+}}, \sum_{j=1}^{m} \frac{b_{1 j}^{+}}{\sum_{j=1}^{m} b_{i j}^{+}}, \Lambda, \sum_{j=1}^{m} \frac{b_{1 j}^{+}}{\sum_{j=1}^{m} b_{i j}^{+}}\right)^{T}
$$

In order to calculate the indicator weights, further normalization of is done as follows. Eq. 6 and Eq. 7 show the minimum and maximum eigenvectors.

$$
\begin{aligned}
& x^{-}=\left(x_{1}^{-}, x_{2}^{-}, \Lambda, x_{m}^{-}\right)^{T} \\
& x^{+}=\left(x_{1}^{+}, x_{2}^{+}, \Lambda, x_{m}^{+}\right)^{T}
\end{aligned}
$$

Eq. 8 is used to assess the consistency of a matrix. The permissible range of inconsistency of a matrix will be determined by using the consistency test.

$$
\alpha=\sqrt{\sum_{j=1}^{m} \frac{1}{\sum_{i=1}^{m} b^{+}}}, \beta=\sqrt{\sum_{j=1}^{m} \frac{1}{\sum_{i=1}^{m} b^{-}}}
$$

8

If $0 \leq a \leq 1 \leq \beta$, the matrix meets the consistency condition. If the consistency condition is not satisfied, the original judgment matrix should be reviewed until the condition is satisfied.

\subsubsection{Uniformization of interval weight}

The weight vector of the interval judgment matrix can be expressed by Eq. 9 .

$$
S_{i j}=\left[S_{i j}{ }^{-}, S_{i j}{ }^{+}\right]=\left[\alpha x_{i j}{ }^{-}, \beta x_{i j}{ }^{+}\right]=\left(\begin{array}{cc}
\alpha x_{1}- & \beta x_{1}{ }^{+} \\
\vdots & \vdots \\
\alpha x_{m}- & \beta x_{m}{ }^{+}
\end{array}\right)
$$

9

Then $V\left(S_{i j k}>S_{i j}\right) \geq 0$ indicates the probability $\left(P_{i j k}\right)$ of $S_{i j k}>S_{i j k}$. The probability $\left(P_{i j k}\right)$ is calculated as follows by using the simple associative series method, 


$$
\left\{\begin{array}{c}
P_{i j l}=1 \\
P_{i j k}=V\left(S_{i j k} \geq S_{i j l}\right)=\frac{2\left(S_{i j k}^{+}-S_{i j l}^{-}\right)}{\left(S_{i j k}^{+}-S i_{j k}^{-}\right)+\left(S_{i j l}^{+}-S_{i j l}^{-}\right)}
\end{array}\right.
$$

10

Where, $i, j=1,2, \ldots, \mathrm{m}, P_{i j k}$ denotes a single ranking of $k$ indicators for the $i j$ level of indicators. The weights $\omega_{i j k}$ are obtained after normalization

$$
w_{i j k}=\frac{P_{i j k}}{\sum_{k=1}^{m} P_{i j k}}
$$

11

\subsubsection{Index factor}

Different assessment indicators have different units. To obtain a reliable assessment, the actual value of each indicator factor $(X)$ was transformed into a fractional value $\left(Q_{i}\right)$ according to the indicator value, calculated as defined in Eqs. 12 and 13.

$$
\left\{\begin{array}{cc}
Q_{i}=100 & X \leq G_{1} \\
Q_{i}=100-\frac{10\left(X-G_{1}\right)}{\left(G_{2}-G_{1}\right)} & G_{1}<X \leq G_{2} \\
Q_{i}=90-\frac{10\left(X-G_{2}\right)}{\left(G_{3}-G_{2}\right)} & G_{2}<X \leq G_{3} \\
Q_{i}=80-\frac{20\left(X-G_{3}\right)}{3\left(G_{3}-G_{1}\right)} & G_{3}<X
\end{array}\right.
$$

where, $G_{1}, G_{2}$ and $G_{3}$ are indicator value 1 , indicator value 2 and indicator value 3 , respectively.

$$
Q=\sum_{k=1}^{l} \sum_{j=1}^{n} \sum_{i=1}^{m} Q_{i j k} \times \omega_{i j k}
$$

13

where, $m$ is the total number of indicators at the criterion level, $n$ is the total number of factors at the indicator level for a subset of the criterion level, and / is the total number of factor levels for a subset of the indicator level.

\section{Case Study}




\subsection{Application of the ECM-EAHP}

To further understand the model developed, the safety monitoring data of the concrete face rockfill dam of Jilintai first cascade hydropower station (Yang et al., 2010) has been employed in the proposed ECMEAHP model. When using the ECM generator, considering the uncertainty and randomness during the calculation process using the cloud model, 30,000 cloud drops were used to generate the cloud map. The process was repeated 50 times, and the average of these calculations was selected as the final cloud map. In total, there are 35 indicators, and each indicator has one extended cloud map. The extended cloud maps for four indicators are presented in Figures 4a-4d.

The indicator values obtained from the extended cloud model are presented in Table 3, which includes indicators for seepage, settlement, face deformation and reinforcement stress.

Table 3

Indicator values

\begin{tabular}{|lllll|}
\hline Indicator & $\begin{array}{l}\text { Indicator value } \mathbf{1} \\
(\mathbf{G 1 )}\end{array}$ & $\begin{array}{l}\text { Indicator value 2 } \\
(\mathbf{G} 2)\end{array}$ & $\begin{array}{l}\text { Indicator value 3 } \\
(\mathbf{G 3})\end{array}$ & Units \\
\hline Seepage & 120.50 & 132.91 & 145.93 & $\left(\mathrm{L.s}^{-1}\right)$ \\
\hline Settling & 583.67 & 589.37 & 596.88 & $(\mathrm{~mm})$ \\
\hline Face deformation & 46.53 & 52.99 & 57.58 & $(\mathrm{~mm})$ \\
\hline $\begin{array}{l}\text { Reinforcement } \\
\text { stress }\end{array}$ & -43.45 & -44.65 & -45.91 & $(\mathrm{MPa})$ \\
\hline
\end{tabular}

\subsection{Calculation indicator weights}

Based on the results described above, the judgement matrix was determined, as shown in Tables 4 - 6 .

Table 4

Judgement matrix and weights for level 1

\begin{tabular}{|lllllll|}
\hline Indicator level 1 & $C_{1}$ & $C_{2}$ & $C_{3}$ & $C_{4}$ & $C_{5}$ & Weight \\
\hline$C_{1}$ & $<1.0,1.0>$ & $<1.1,1.2>$ & $<1.3,1.5>$ & $<1.6,1.9>$ & $<1.7,2.0>$ & 0.3211 \\
$C_{2}$ & $<0.83,0.91>$ & $<1.0,1.0>$ & $<1.18,1.25>$ & $<1.3,1.58>$ & $<1.55,1.67>$ & 0.3036 \\
$C_{3}$ & $<0.67,0.77>$ & $<0.8,0.85>$ & $<1.0,1.0>$ & $<1.19,1.3>$ & $<1.31,1.50>$ & 0.2176 \\
$C_{4}$ & $<0.53,0.63>$ & $<0.63,0.77>$ & $<0.77,0.84>$ & $<1.0,1.0>$ & $<1.06,1.30>$ & 0.1035 \\
$C_{5}$ & $<0.5,0.59>$ & $<0.6,0.76>$ & $<0.67,0.76>$ & $<0.77,0.94>$ & $<1.0,1.0>$ & 0.0542 \\
\hline
\end{tabular}


Table 5

Judgement matrix and weights for level 2

\begin{tabular}{|lllll|}
\hline Indicator level 2 & $C_{21}$ & $c_{22}$ & $c_{23}$ & Weighting \\
\hline$C_{21}$ & $<1.0,1.0>$ & $<1.5,1.7>$ & $<1.5,1.7>$ & 0.7275 \\
\hline$C_{22}$ & $<0.59,0.67>$ & $<1.0,1.0>$ & $<1.0,1.1>$ & 0.1665 \\
\hline$C_{23}$ & $<0.59,0.67>$ & $<0.91,1.0>$ & $<1.0,1.0>$ & 0.1060 \\
\hline
\end{tabular}

Table 6

Judgement matrix and weights for level 3

\begin{tabular}{|llllll|}
\hline Indicator level 3 & $C_{221}$ & $C_{222}$ & $C_{223}$ & $C_{224}$ & Weighting \\
\hline$C_{221}$ & $<1.0,1.0>$ & $<1.1,1.3>$ & $<1.1,1.5>$ & $<1.1,1.2>$ & 0.4686 \\
$C_{222}$ & $<0.87,0.91>$ & $<1.0,1.0>$ & $<1.0,1.15>$ & $<1.0,1.15>$ & 0.2314 \\
$C_{223}$ & $<0.87,0.91>$ & $<0.87,1.0>$ & $<1.0,1.0>$ & $<1.0,1.15>$ & 0.1783 \\
$C_{224}$ & $<0.87,0.91>$ & $<0.87,1.0>$ & $<0.87,1.0>$ & $<1.0,1.0>$ & 0.1217 \\
\hline
\end{tabular}

Values in Tables 4-6 were obtained by using Eq. 4-Eq. 7. The corresponding eigenvectors are shown in Table 7.

Table 7

Eigenvectors for selected indicator level

\begin{tabular}{|llllll|}
\hline Guideline level & \multicolumn{2}{l}{ Indicator level } & \multicolumn{2}{l|}{ Factor level } \\
\hline 0.2675 & 0.2713 & 0.4403 & 0.4475 & 0.2771 & 0.2676 \\
\hline 0.2340 & 0.2288 & 0.2849 & 0.2814 & 0.2494 & 0.2531 \\
\hline 0.1982 & 0.1933 & 0.2749 & 0.2712 & 0.2410 & 0.2523 \\
\hline 0.1593 & 0.1618 & - & - & 0.2326 & 0.2430 \\
\hline 0.1412 & 0.1449 & - & - & - & - \\
\hline
\end{tabular}

Both $\alpha$ and $\beta$ values were calculated using Eq. 8 for testing the consistency of the extension of the judgment matrix, and the results are shown in Table 8. 
Table 8

Consistency checking - $\alpha$ and $\beta$

\begin{tabular}{|clll|}
\hline & Guideline level & Indicator level & Factor level \\
\hline $\mathrm{a}$ & 0.94 & 0.96 & 0.97 \\
$\beta$ & 1.05 & 1.04 & 1.03 \\
\hline
\end{tabular}

One can see from Table 8 , the values of $a$ and $\beta$ satisfy $0 \leq a \leq 1 \leq \beta$, and the consistency test for the judgment matrix is satisfied. The eigenvectors for the indicator level in Table 7 are substituted into Eq. 9Eq. 11 to calculate $P_{i}$ and are then normalized to determine indicator single level weights, as shown in Table 4 - Table 6. Similarly, other indicator (in Table 1) single level weights are obtained. The results are shown in Figure 5.

\subsection{Calculation of indicator level scores}

Taking the raw indicator data into Eq. 12 allows obtaining the assessment scores of the indicators. Taking these assessment scores into Eq. 13 allows obtaining the assessment scores of the indicator level and the overall assessment scores, shown in Figures $6 \mathrm{a}-6 \mathrm{~d}$.

The developed CM-EAHP model has been used for the safety assessment of the Jilintai concrete face rockfill dam. Results showed that due to the decrease in the reservoir water level and the repair projects of the Jilintai dam in recent years, seepage decreased gradually. Results indicated that both the seepage through the dam body and around the dam shoulders is in a safe range, which is consistent with the results obtained from the model calculation.

There was a partial landslide in the back slope of the dam. According to data collected from the automated monitoring system, the horizontal displacement of the dam body has an increasing trend in the past two years. The dam settlement is stable, which may explain the gradual decrease in the local dam deformation score $\left(C_{3}\right)$ from the model monitoring. Overall, it can be concluded that this concrete face rockfill dam is in good condition, and this assessment agrees with the model results $(C)$.

\subsection{Comparison of results using different models 4.3.1 The cloud model (CM)}

The CM assessment method is usually comprised of the following three steps (Zhang et al., 2014): step 1 , selection of the original data of the assessment indicators in order to process the cloud transformation; step 2, the establishment of the cloud model of the assessment indicators; and steps 3, comparison of results based on the cloud model of the comprehensive assessment and those of the cloud model of the assessment indicator set. Figure 7 illustrates the process.

The process described in Figure 7 was employed to perform safety assessment of the Jilintai concrete face rockfill dam using the $\mathrm{CM}$. Results of this analysis are presented in Figure 8. 
From the results shown in Figures 6 and 8, it can be seen that assessment results of the operation using both the ECM-EAHP method and the CM method are both level 2, implying that the assessment results are consistent. One can say that the ECM-EAHP method is feasible and effective, and more comprehensive than the traditional dam safety assessment methods which only give one overall result of the assessment level. Additionally, the ECM-EAHP method is more flexible, and can provide more detailed information such as indicator values. Also, the indicator values can be updated as the data is selected, and can provide rapid feedback and early warning of the dam's current condition when more adverse conditions are encountered.

\subsubsection{Typical small probability method}

The early warning results obtained by using the ECM method were compared to those obtained by using the typical small probability method (Wu et al., 1989). For the water level indicator, the early warning value obtained using the typical small probability method $(a=2 \%)$ was 1419.93 ; the early warning value obtained using the ECM was 1420.24 . Also, for the horizontal displacement indicator, the early warning value obtained using the typical small probability method $(a=2 \%)$ was 94.067 ; and the early warning value obtained using the ECM was 94.101. These results showed that one can get nearly the same results by using the typical small probability method and the Extended Cloud Model method. However, the Extended Cloud Model is more flexible and less computationally expensive.

\section{Conclusions}

Dam safety assessment is a complicated process which should consider multi-factors, multi-levels, stochastic and fuzzy aspects. The Cloud Model (CM) can better transform the uncertainty and stochastic qualitative aspects during the dam safety monitoring process into quantitative results. In the present study, the ECM-EAHP method has been developed and applied to assess dam safety trend of the Jilintai concrete face rockfill dam.

Assessment results by using both the ECM-EAHP method and the CM method showed that the operation level of the Jilintai concrete face rockfill dam is level 2. Results of both methods indicate that the Jilintai concrete face rockfill dam has a good operating condition. The horizontal displacement of the dam body has an increasing trend in the past two years. Results showed that other indicators were in a safe operating condition. The selection of indicator values was consistent with the results of the typical small probability method. The cloud model assessment method is mostly a one-time assessment, and the workload is greater if a secondary assessment process should be conducted. The ECM-EAHP method is a visual assessment method for assessing dam safety trends. The ECM-EAHP method not only provides an overall assessment of the dam's safety level, but also provides a detailed visualization of the dam's operating conditions reflected by each factor. The ECM-EAHP method can be combined with an automated dam safety monitoring platform to visualize dam safety trends, providing a methodological option for an integrated system of automated dam safety monitoring and early warning. 


\section{Declarations}

-We declare that this manuscript is an original research work.

- This manuscript has never been submitted to other journals and conferences for possible publication.

- There is not any interest that is directly or indirectly related to this research work submitted for publication.

- The study does not involve the use of humans or animals.

- There is not any potential conflict of interest.

- Author Contributions: Conceptualization, L.S., J.W., J.S., and M.D.; methodology, L.S., J.W., J.S. and M.D.; validation, L.S., J.W., J.S., and M.D.; formal analysis, L.S. and J.W.; investigation, L.S., J.W. and J.S.; resources, L.S., J.W. and J.S.; writing-original draft preparation, L.S., J.W. and J.S.; writing-review and editing, J.S. and M.D.; supervision, J.W. and J.S.; funding acquisition, J.W. All authors have read and agreed to the published version of the manuscript.

- Funding: This research is supported by the National Natural Science Foundation of China (Grant Nos. 51879065). The authors are grateful for the financial support.

- Availability of data and materials: all data and materials are available upon the requirement.

\section{References}

1. Araujo JC, Dias FF (2021) Multicriterial method of AHP analysis for the identification of coastal vulnerability regarding the rise of sea level: case study in Ilha Grande Bay, Rio de Janeiro, Brazil, Natural Hazards, 1-20,

2. Chen B, Huang Z, Bao T, Zhu Z (2021) Deformation early-warning index for heightened gravity dam during impoundment period. Water Science and Engineering 14(01):54-64

3. Dong W, Zhang S, Zhu F Evaluation of road performance of asphalt mixtures based on topological hierarchical analysis,Journal of Jilin University (Engineering Edition):1-8

4. Gu C, Su H, Liu H (2018) A review of research on service risk analysis and management of dams. Chinese Journal of Hydraulic Engineering 49(01):26-35

5. Gu H, Zhu Y, Gu C, Huang X, Cao W (2020) A method for diagnosing the health status posture of concrete dams. Chinese Journal of Hydraulic Engineering 51(08):957-966

6. Gu Y, Wang S, Pang. Q, Wang Y, Wu Y (2017) Research on the formulation of early warning indicators for concrete dam deformation based on risk management. Chinese Journal of Hydraulic Engineering 48(04):480-487

7. He J, Gao Q (2018) An improved cloud merging algorithm adapted to dam health diagnosis. Journal of Wuhan University (Information Science Edition) 43(07):1022-1029 
8. He J, Gao Q, Shi Y (2016) A multi-level comprehensive evaluation method for dam safety based on cloud model. System Engineering Theory and Practice 36(11):2977-2983

9. Li D, Meng H, Shi X (1995) Membership Clouds and Membership Cloud Generators. Journal of Computer Research and Development 32(6):15-20

10. Li J, Wang M, Xu P, Xu P (2014) Classification of surrounding rock stability based on cloud mode. Journal of Geotechnical Engineering 36(01):83-87

11. Li X, Zhong D, Ren B, Deng S, Zhu Y (2017) Research on the evaluation of the irrigability of dam foundation rock based on fuzzy RES-cloud model. Chinese Journal of Hydraulic Engineering 48(11):1311-1323

12. Liu Z, Shao J, Xu W, Xu F (2014) Comprehensive Stability Evaluation of Rock Slope Using the Cloud Model-Based Approach,Rock Mechanics and Rock Engineering, 47(6),

13. Neji Nouha N, Ben AR, Habib A (2021) Water erosion hazard mapping using analytic hierarchy process (AHP) and fuzzy logic modeling: a case study of the Chaffar Watershed (Southeastern Tunisia),Arabian Journal of Geosciences, 14(13),

14. Peng T, Deng H (2020) Comprehensive evaluation on water resource carrying capacity in karst areas using cloud model with combination weighting method: a case study of Guiyang, southwest China. Environ Sci Pollut Res 27:37057-37073

15. Radhika EG, Sudha Sadasivam G (2021) Budget optimized dynamic virtual machine provisioning in hybrid cloud using fuzzy analytic hierarchy process. Expert Systems with Applications, 183,

16. Saaty TL, Zhang L (2016) The Need for Adding Judgment in Bayesian Prediction. International Journal of Information Technology and Decision Making 15(4):733-761

17. Wu Y, Chu H, Xu C (2021) Risk assessment of wind-photovoltaic-hydrogen storage projects using an improved fuzzy synthetic evaluation approach based on cloud model: A case study in China,Journal of Energy Storage, Vol. 38,10258,

18. Wu Z, Lu Y (1989) Safety monitoring indicators of dams using prototype observation feedback.Journal of Hohai University,1989(06):29-36,

19. Yan F, Zhang Q, Ye S, Ren B (2019) A novel hybrid approach for landslide susceptibility mapping integrating analytical hierarchy process and normalized frequency ratio methods with the cloud model Geomorphology, 327,

20. Yan F, Xu K (2019) Methodology and case study of quantitative preliminary hazard analysis based on cloud model,Journal of Loss Prevention in the Process Industries, 60,

21. Yang G, Guo X, Gao W, Ma Y (2010) Safety monitoring design of concrete panel gravel dams in Jilintai Grade I hydropower station. Water Resources and Hydropower Technology 41(06):28-30

22. Yang J, Wu Z (2002 (01)) Current status and development of domestic and international research on dam safety monitoring, Journal of Xi'an University of Technology, : 26-30, 2002

23. Yee HJ et al (2021) Synthesis of wastewater treatment process (WWTP) and supplier selection via Fuzzy Analytic Hierarchy Process (FAHP).Journal of Cleaner Production, 314, 
24. Zhang Q, Zhang Y, Zhong M (2014) Multi-level fuzzy integrated evaluation of reservoir-induced earthquake risk based on cloud model. Chinese Journal of Hydraulic Engineering 45(01):87-95

\section{Figures}

\begin{tabular}{|c|c|}
\hline & Reservoir water level $\left(\mathrm{c}_{11}\right)$ \\
\hline \multirow[t]{2}{*}{ Dam safety monitoring(C) } & weight $\left(\mathrm{w}_{11}\right)$ \\
\hline & Seepage $\left(\mathrm{C}_{21}\right)$ \\
\hline & weight $\left(\mathrm{w}_{21}\right)$ \\
\hline \multirow{2}{*}{$\begin{array}{c}\text { Environment variable }\left(\mathrm{C}_{1}\right) \\
\text { weight }\left(\mathrm{w}_{1}\right)\end{array}$} & Dam foundation seepage $\left(C_{22}\right)$ \\
\hline & weight $\left(\mathrm{w}_{22}\right)$ \\
\hline & Seepage around dam $\left(C_{23}\right)$ \\
\hline Dam seepage $\left(C_{2}\right)$ & weight $\left(\mathrm{w}_{23}\right)$ \\
\hline weight $\left(\mathrm{w}_{2}\right)$ & Horizontal displacement $\left(\mathrm{C}_{31}\right)$ \\
\hline & weight $\left(w_{31}\right)$ \\
\hline $\begin{array}{c}\text { Dam deformation }\left(\mathrm{C}_{3}\right) \\
\text { weight }\left(\mathrm{w}_{3}\right)\end{array}$ & Sedimentation $\left(\mathrm{C}_{32}\right)$ \\
\hline & weight $\left(\mathrm{w}_{32}\right)$ \\
\hline \multirow{2}{*}{$\begin{array}{c}\text { Face deformation }\left(\mathrm{C}_{4}\right) \\
\text { weight }\left(\mathrm{w}_{4}\right)\end{array}$} & Perimeter joint $\left(\mathrm{C}_{41}\right)$ \\
\hline & weight $\left(\mathrm{w}_{41}\right)$ \\
\hline \multirow{8}{*}{$\begin{array}{c}\text { Stress-strain }\left(C_{5}\right) \\
\text { weight }\left(\mathrm{w}_{5}\right)\end{array}$} & Vertical joint $\left(\mathrm{C}_{42}\right)$ \\
\hline & weight $\left(\mathrm{w}_{42}\right)$ \\
\hline & Concrete face deformation $\left(\mathrm{C}_{43}\right)$ \\
\hline & weight $\left(\mathrm{w}_{43}\right)$ \\
\hline & Reinforcement stress $\left(\mathrm{C}_{51}\right)$ \\
\hline & weight $\left(\mathrm{w}_{51}\right)$ \\
\hline & Concrete strain $\left(\mathrm{C}_{52}\right)$ \\
\hline & weight $\left(\mathrm{w}_{52}\right)$ \\
\hline
\end{tabular}

\section{Figure 1}

Mapping of assessment for the dam safety 


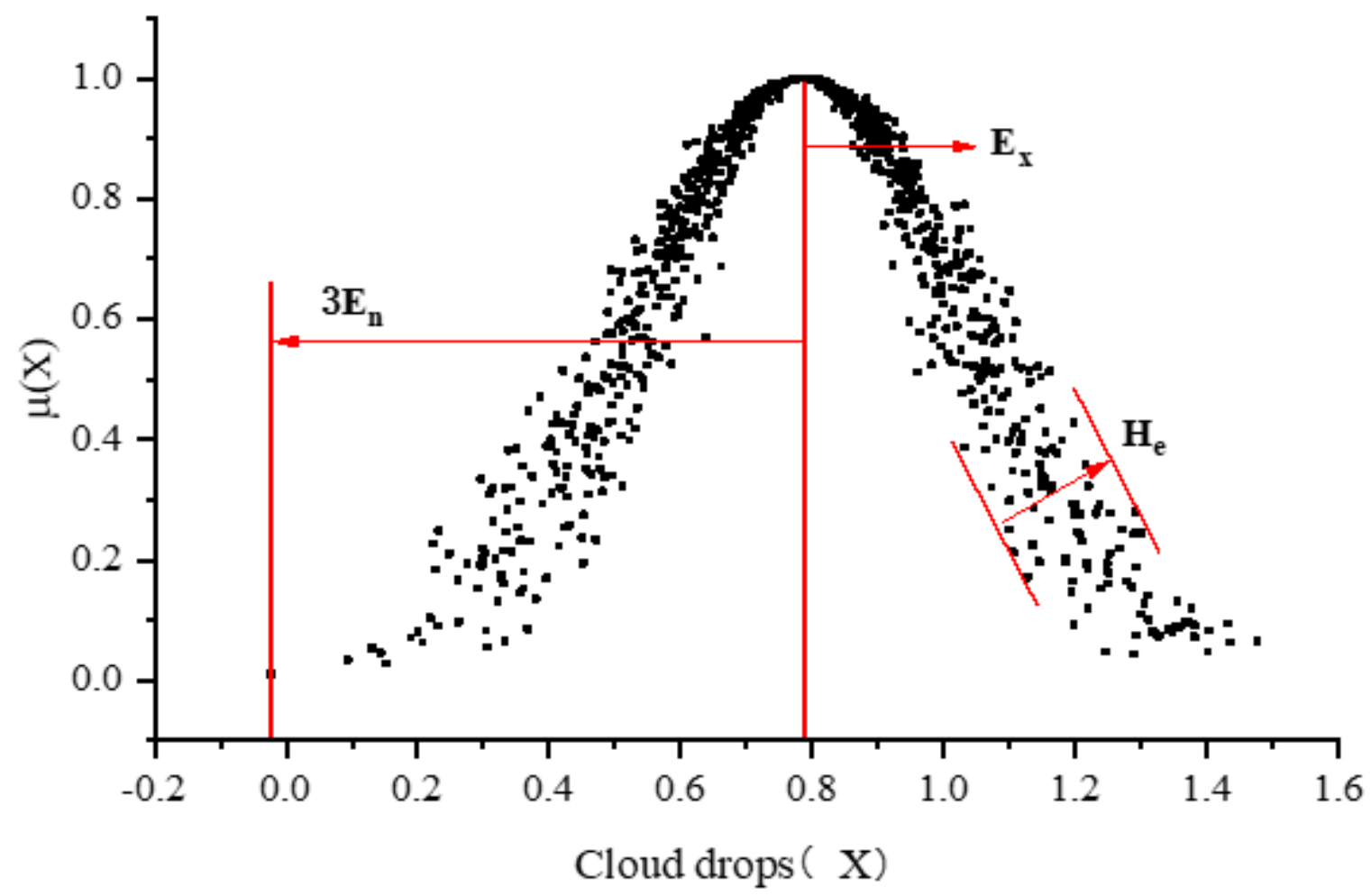

Figure 2

Digital features of the cloud model
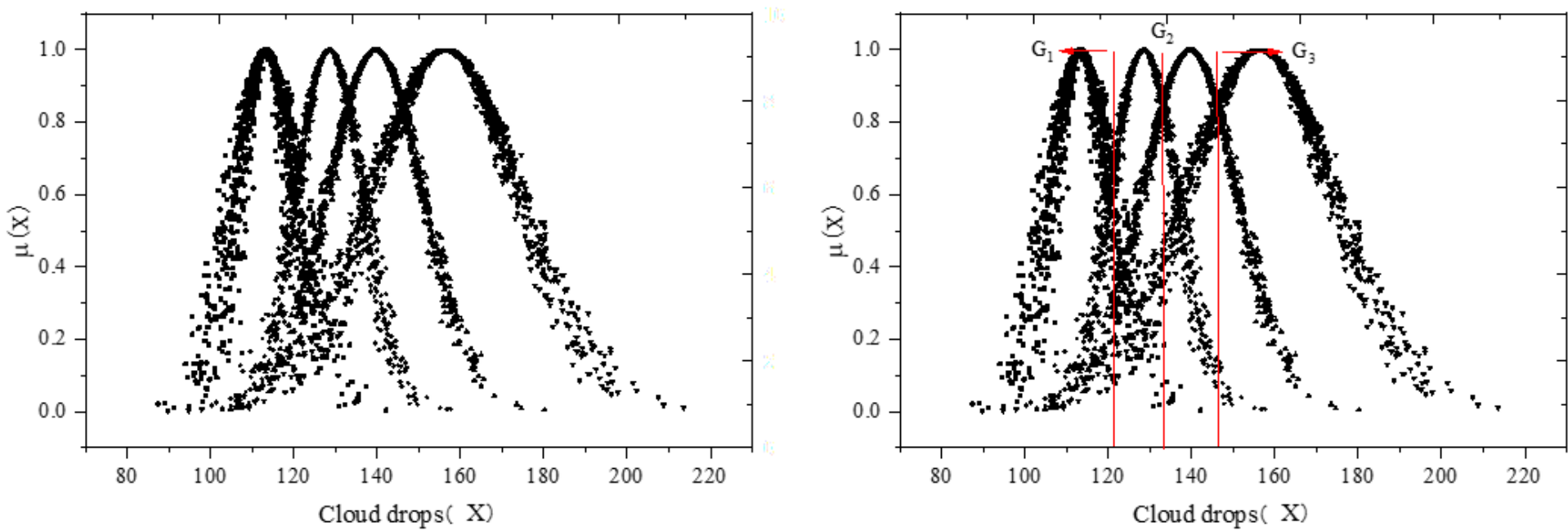

Figure 3

The index affiliation scope of the cloud model (a) and indicator values (b) 


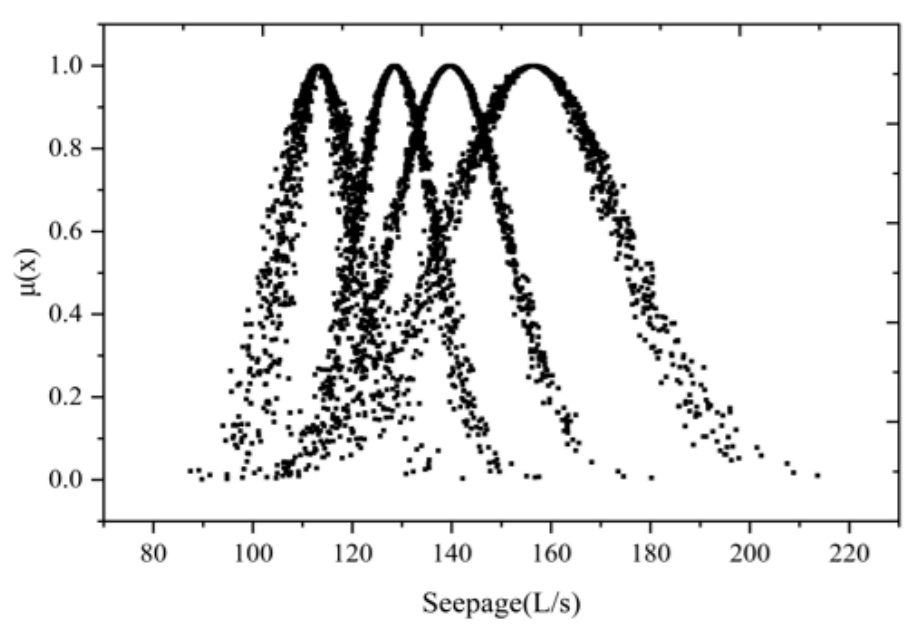

(a)

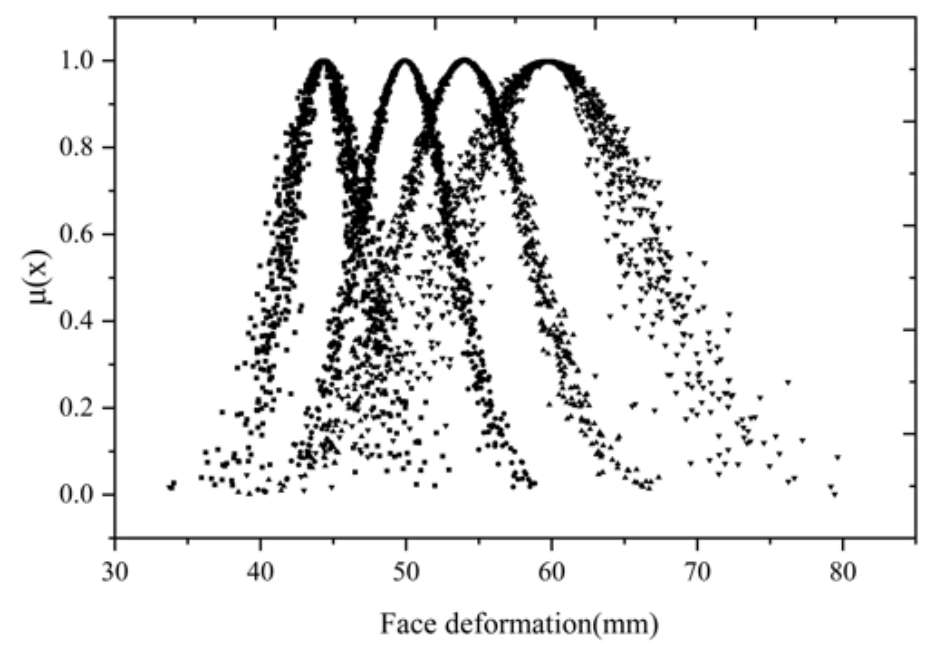

(c)

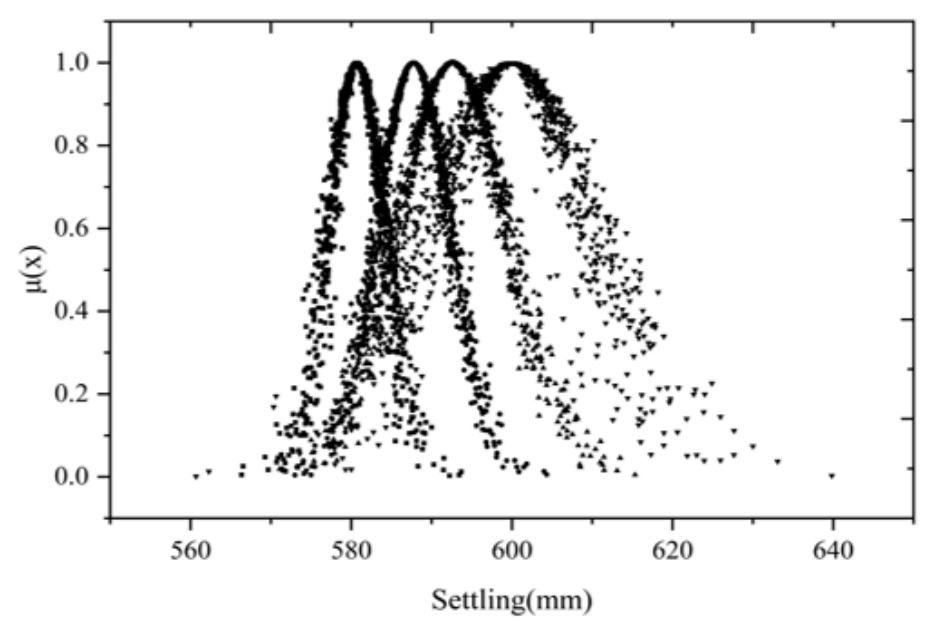

(b)

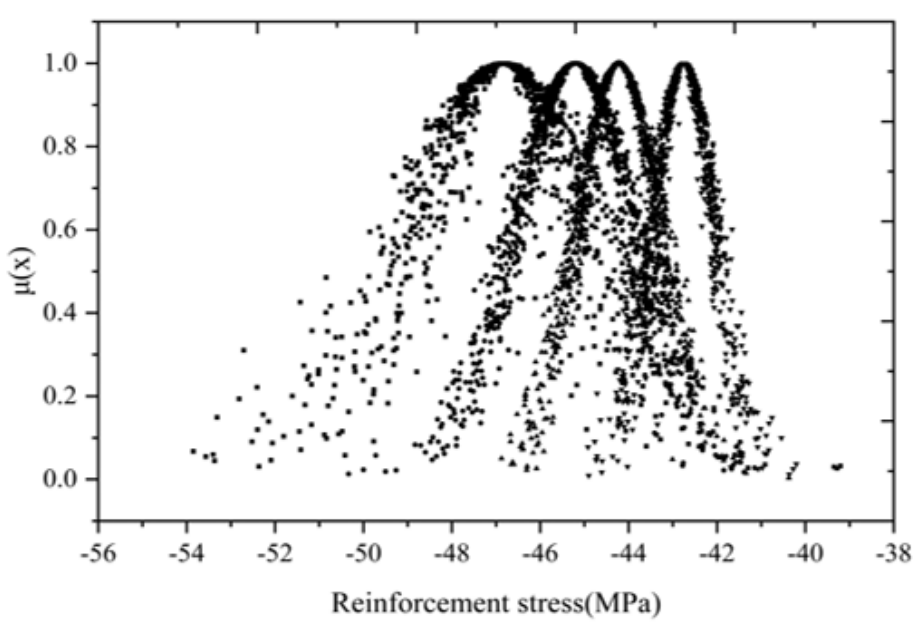

(d)

Figure 4

Indicators for extended cloud model 


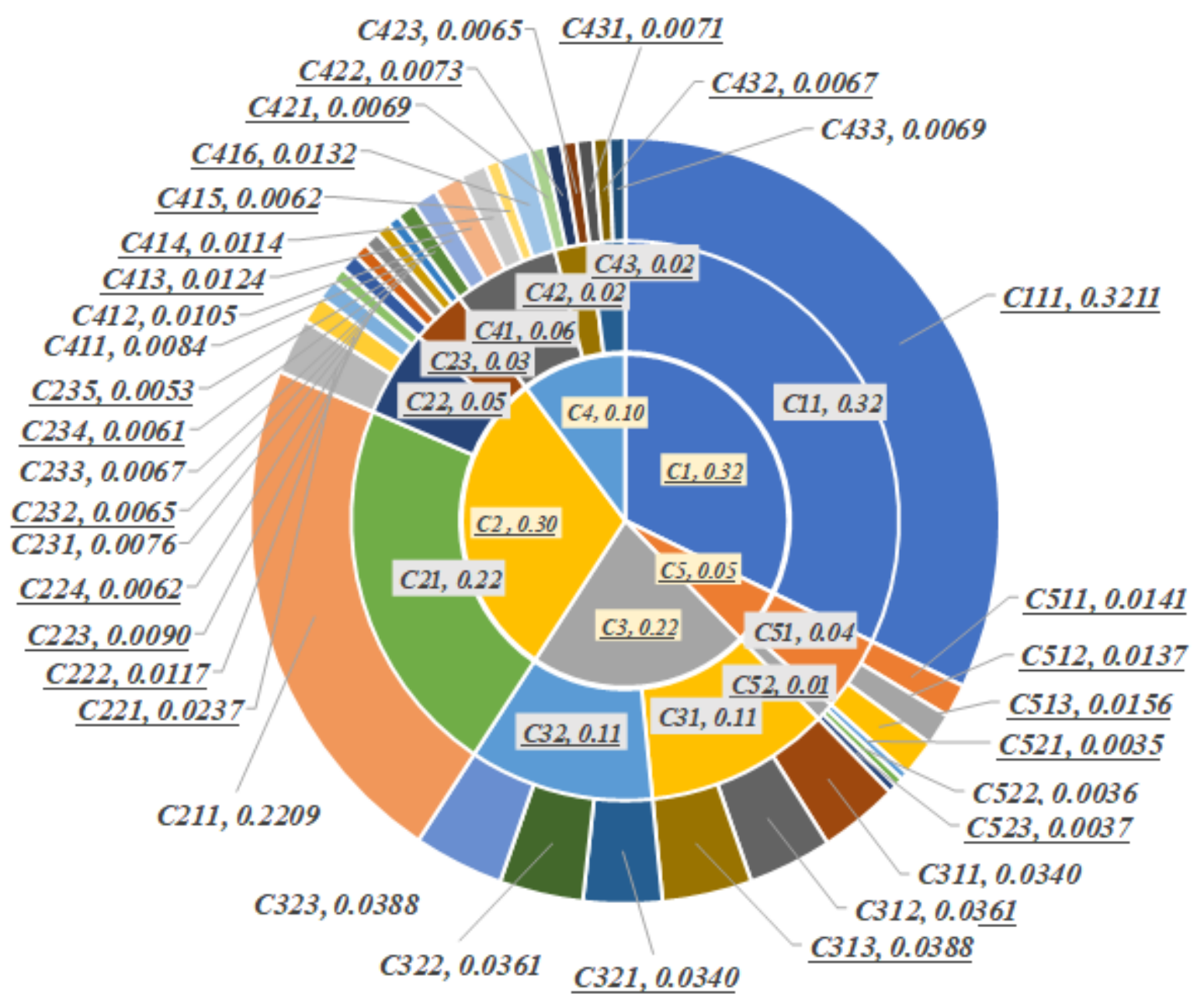

Figure 5

Indicator weights

Figure 6

Score chart for dam safety trend in 2020 - (a) - (d) identify the quarters in the year. 


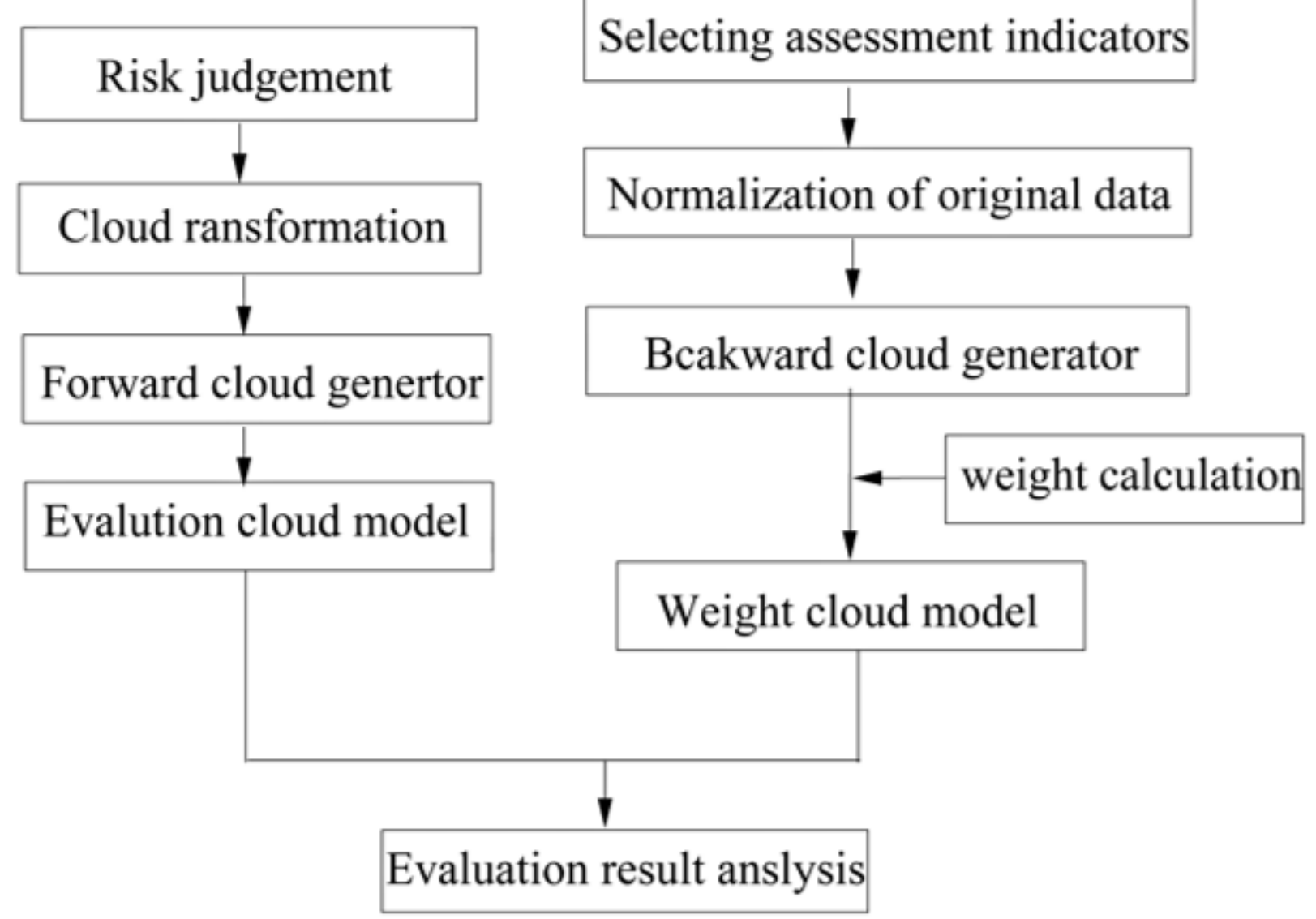

Figure 7

Flow chart of the traditional cloud model assessment 


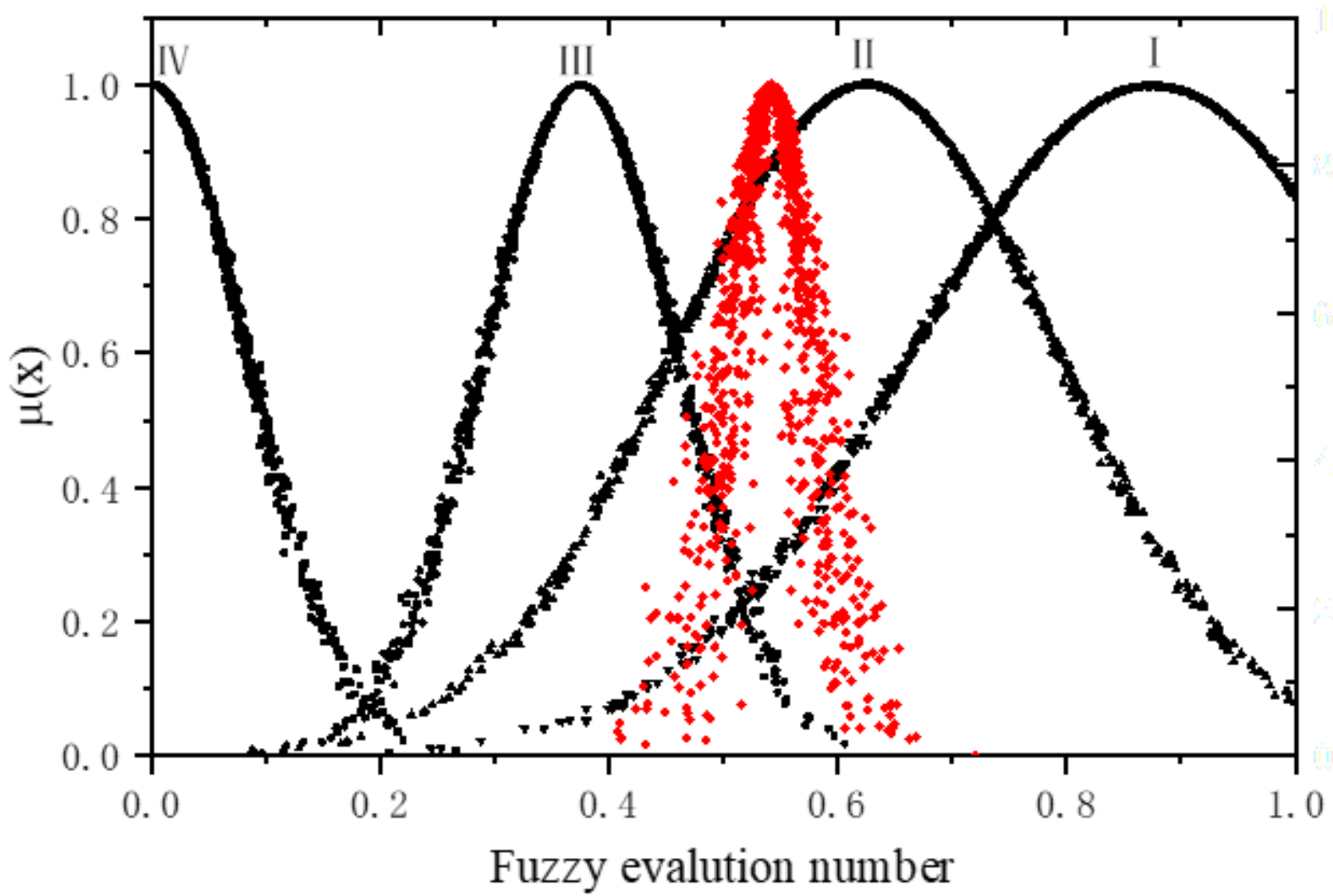

Figure 8

Assessment of safety level of the Jilintai dam using the Cloud Model 